\title{
An Assessment of Leading Health Indicators in Select General Readership Magazines, 2005-2008
}

\author{
Jeanne Freeman and Ying Li \\ Western Washington University
}

\begin{abstract}
Mass media can play an important role in setting public agenda and stimulating public attention to issues. Purpose: To assess health-related articles in select mass-circulating general readership magazines, and identify which of the Leading Health Indicators (LHI) each of them addresses. Methods: Four of the top 35 general readership magazines listed in the 2007 Magazine Publishers of America were considered, and included Reader's Digest, Time, Newsweek, and U.S. News and World Report. ProQuest was searched to obtain all health-related articles $(n=55)$ available in these magazines between July 2005 and August 2008. Articles were assessed in regards to LHIs, sources of information, presentation of statistics and risk factors, and citation of prevention measures. Results: The most frequent LHIs addressed were overweight and obesity (21.4\%) and mental health (19\%). The most frequent source of information was experts such as MDs and PhDs (92.9\%). Incidence and prevalence of LHIs were frequently presented, while risk factors were presented in less than 25\% of the articles. Conclusion: Mass media can be a valuable tool for dissemination and stimulation of public attention to high priority public health issues. Enhanced coordination is needed between health educators and members of the press to ensure accurate and universally relevant health information in general readership magazines.
\end{abstract}

(C) 2011 Californian Journal of Health Promotion. All rights reserved.

Keywords: mass media; prevention; leading health indicators; risk factor

\section{Introduction}

The World Health Organization's Ottawa Charter for Health Promotion, presented in 1986, was one of the first efforts to encourage partnerships between the health sector and the mass media in communicating health information to the public. The process of disseminating policy-related information through media, especially where the aim is to promote action, change a policy, or alter the public's view of an issue, is termed media advocacy (Breslow, 2002). Proponents of media advocacy have lobbied for health message exposure and accuracy of information presented. They have also lobbied for the media to bear the responsibility to frame the content of messages, and to advance public policies aimed at advancing health. Despite these efforts, mass media continues to be a source of both hope and frustration in promoting health and wellness to its readers (Grilli, Ramsay, \& Minozzi, 2002).
Beyond informing individuals, mass media can play an important role in setting public agenda, as issues reported in the media are more likely to be seen as important and meritorious of public discourse (Frost et al., 1997). Further, the amount of copy space is an important indicator of perceived newsworthiness (McCombs \& Shaw, 1972). As such, media advocacy is a powerful tool that can be used to promote an issue in order to influence policymakers and encourage positive social change (Wallack \& Dorfman, 1996).

Research spanning the last two decades indicates that mass media plays an important role in people's health. Various media formats (e.g. newspapers, television programming, social media, and the Internet) can influence how health-related information is disseminated, as well as how health behaviors and health information are perceived by consumers. Due to the diversity and proliferation of media delivery 
channels, mass media's influences on health have been mixed with both positive and negative outcomes regarding consumer knowledge and attitudes (Maibach, 2007).

\section{Health and the Media}

Exposure to media messages has been linked to increased protective health-related outcomes for skin cancer beliefs and behaviors (Hay, Coups, Ford, \& DiBoneventura, 2009), cervical cancer screenings (Anderson, Mullins, Siahpush, Spittal, \& Wakefield, 2009), health service utilization (Grilli, et al., 2002), and HIV/AIDS testing (Noar, Palmgreen, Chabot, Dobransky, \& Zimmerman, 2009). However, exposure to media messages has also been linked to negative outcomes such as the onset of eating disorder behaviors (Martinez-Gonzalez, Gual, Lahortiga, Alonso, Irala-Estevez, \& Cervera, 2003), beliefs about the social acceptability of suicide (Phillips, 1974), and negative perceptions of the value of HIV/AIDS testing (Noar et al., 2009). Although it is unclear whether or not utilizing mass media has a positive impact on health perceptions and behaviors, researchers continue to pursue this strategy for message dissemination.

Employment of mass media by researchers is most often done as part of program implementation. In studies where researchers develop the disseminated messages, identify the target population of interest, and control the channels of distribution, the accuracy of the health information tends to be high and often results in positive impacts (Anderson et al., 2009; Hay et al., 2009; Noar et al., 2009). However, research indicates that when mass media sources take it upon themselves to summarize findings of studies, they often report the findings inaccurately, and this is associated with negative health outcomes for the consumer (Martinez-Gonzalez, et al., 2003; Noar et al., 2009). This may, in part, be a result of the media frequently misrepresenting or distorting information about the causes of mortality and associated risk factors. As such the media consumers can develop a skewed perception of health issues and the relative importance of these issues to each individual (Frost, et al., 1997).

\section{Leading Health Indicators (LHIs) in the Media}

Numerous health-related topics have been covered in the mass media and have received national and global attention. While reports about global warming, swine flu, HIV/AIDS, and genomics are health-related topics that have been covered in the media, these topics have been focused on due to the fact they are "hot topics". As such, there is a lack of media attention that is afforded to health issues that may not be congruent with these perceived hot topics.

Each decade the U.S. Department of Health and Human Services releases the Healthy People document to guide national health initiatives for the next ten years. Healthy People 2010 included a set of 10 high priority public health issues in the United States called the Leading Health Indicators (LHIs). See Table 1. These same LHIs are the focus for the U.S. for the Healthy People 2020 publication.

\section{Table 1}

\section{Leading Health Indicators (LHIs)}

\begin{tabular}{|c|c|}
\hline - Physical Activity & $\begin{array}{l}\text { - Overweight and } \\
\text { Obesity }\end{array}$ \\
\hline - Tobacco Use & - Substance Abuse \\
\hline $\begin{array}{l}\text { - Responsible } \\
\text { Sexual Behavior }\end{array}$ & - Mental Health \\
\hline $\begin{array}{l}\text { - Injury and } \\
\text { Violence }\end{array}$ & $\begin{array}{l}\text { - Environmental } \\
\text { Quality }\end{array}$ \\
\hline - Immunization & $\begin{array}{l}\text { - Access to Health } \\
\text { Care }\end{array}$ \\
\hline
\end{tabular}

Note. U.S. Department of Health and Human Services. Leading Health Indicators. Available at: http://www.healthypeople.gov. Accessed September 19, 2008 .

Media attention to LHIs infrequently receives the same level of coverage or attention as other health related topics. However, according to the U.S. Department of Health and Human Services (2000), each LHI is an important health issue by 
itself. One's status for each of the indicators depends, to some extent, on the knowledge people have about their health and how to make improvements; choices people make; where and how people live; and the type, amount, and quality of health care people receive (US DHHS, 2000). To realize improvements in LHIs requires both effective private and public sector support. As such, researchers partnering with mass media indicates an opportunity to catalyze positive health-related changes on a national level. Such collaborations can elevate the importance of LHIs in the minds of the general public.

While multiple studies have been conducted to examine the relationship between mass media and health, most of them have been focused on one or two health issues of interest as determined by the researcher (Anderson, et al., 2009; Hornik, Jacobsohn, Orwin, Piesse, \& Kalton, 2008; Noar, et al., 2009; SummerlinLong, Goldstein, Davis, \& Shah, 2009; Wallace \& Ballard, 2003; Botta, 2003; Grilli, et al., 2002). There is a lack of research examining mass media's coverage of comprehensive lists of health topics that are universally relevant such as the LHIs.

\section{Magazine Readership}

While mass media includes various methods of dissemination, the act of reading magazines has characteristics that are unique to the print-media genre. Magazines require the reader's cognitive involvement, and the articles provide in-depth coverage, often give additional information resources, have a long shelf life, and are often archived (Dutta-Bergman, 2004a; DuttaBergman, 2004b; Schiavo, 2007; Wright, Sparks, \& O'Hair, 2008). Existing health communication research has shown that the print media, specifically magazines, serve as primary health information resources for various segments of the population (Magazine Publishers of America, n.d.; Rogers, 1999).

On average, a magazine reader in the United States is 43.1 years of age, with an annual household income of approximately $\$ 65,000$ (Association of Magazine Media, n.d.). The readers of specific magazines are frequently subsegmented by subjects of interest, sex, gender, hobbies, professions, race or ethnicity, and age. However, in a study conducted by the Media Management Center at Northwestern University (2004), the top motivators for magazine readers in selecting a publication were the same for males and females, different ethnic and racial groups, and different age groups. Overall, this study found that magazines were chosen because of their perceived value and because consumers perceived that reading the magazine made them smarter. These findings were consistent regardless of whether the magazine consumer was a subscriber, purchased the magazine from a newsstand, or read the magazine at a public location (e.g., a doctor's office or public library).

\section{Purpose of the Study}

The purpose of this study was to assess healthrelated articles and their association with the LHIs, in select mass-circulating general readership magazines. Specifically, three research questions were addressed: (1) Which LHIs are most commonly presented in general readership magazines? (2) Which sources of information are most frequently cited in articles regarding LHIs? (3) What information is presented to readers in articles focused on health information corresponding with LHIs? Investigating this topic is important with the increase in magazine readership, the perceived value placed on the information presented in magazines by their readerships, and the extensive reference to LHIs. Further, the answers to these questions are of continual significance to the field of health education and promotion, as there is a growing rift between the research community and the media.

\section{Methods}

\section{Design and Procedures}

The 2007 Magazine Publishers of America list of leading magazines (by subscription/ circulation rates) was used to select magazines in this comprehensive literature review. For the purpose of this study, general readership magazines were defined as those without a specific target audience based on sex, gender, hobby, age, geographic location, or race and ethnicity. In reviewing the top 35 list based on the criteria identified, four magazines were left 
among the group: Reader's Digest (\#3 circulation rate; 9.68 million subscribers); Time (\#13 circulation rate; 3.37 million subscribers); Newsweek (\#17 circulation rate; 3.12 million subscribers); and U.S. News \& World Report
(\#35 circulation rate; 2.03 million subscribers). The market analyses data for each of these magazines is similar, which supports their comparison for the purpose of this study [See Table 2].

Table 2

Market Analyses Data for Reviewed Magazines

\begin{tabular}{|c|c|c|c|c|}
\hline & Reader's Digest $^{1}$ & Time $^{2}$ & Newsweek $^{3}$ & $\begin{array}{c}\text { U.S. News \& } \\
\text { World Report }\end{array}$ \\
\hline \multicolumn{5}{|l|}{ Sex } \\
\hline Male & $37 \%$ & $52 \%$ & $56 \%$ & $47 \%$ \\
\hline Female & $63 \%$ & $48 \%$ & $44 \%$ & $53 \%$ \\
\hline Average Age & 54 & 48.1 & 49 & 48.3 \\
\hline $\begin{array}{l}\text { Median } \\
\text { Household } \\
\text { Income }\end{array}$ & $\$ 60,756$ & $\$ 73,378$ & $\$ 94,001$ & $\$ 69,749$ \\
\hline Attended College & $61 \%$ & $71.7 \%$ & $73 \%$ & $86 \%$ \\
\hline $\begin{array}{l}\text { Graduated } \\
\text { College }\end{array}$ & $30 \%$ & NA & $46 \%$ & $58 \%$ \\
\hline
\end{tabular}

${ }^{1}$ Reader's Digest Online Media Kit available at http://www.rd.com/mediakit/demographics.html

${ }^{2}$ Time Media Kit available at http://www.timemediakit.com/us/index.html

${ }^{3}$ Newsweek and The Daily Beast Media Kit available at http://mediakit.newsweekdailybeast.com/nw_audience.html

${ }^{4}$ U.S. News \& World Report Media Kit available at http://mediakit.usnews.com/audience/profileonline.php

The ProQuest database was searched to obtain all articles from these magazines, published between 2005 and 2008. Key words or phrases used in the search strategy aligned with the LHIs and included physical activity; overweight or obesity; tobacco; substance use or abuse; sexual behavior or sexual health; mental health; injury or violence; environmental quality or environment; immunization; and access to health care or health care. In addition to reviewing fulltext articles from ProQuest, the hard copy of each magazine from 2005-2008 was reviewed to ensure additional articles were not missing from the ProQuest citation list. To be included in this review, articles were defined as write-ups that had an author, were at least 150 words in length, and were not a part of paid advertisements by drug companies. While there are no industry standards for article length, researchers chose length to be similar to length limitations put forth for scientific abstracts. With this qualifying characteristic, researchers identified a total of 55 health-related articles for evaluation among the four magazine titles reviewed.

\section{Data Analysis}

A content analysis abstraction form was developed by the researchers. This form was used by each researcher to independently collect information from the articles. Data collected from the publications included: sources of information used; incidence/prevalence statistics; risk factors; and prevention measures (primary, secondary, and tertiary). Once each 
researcher had independently collected information from the articles, the data were compared for each article to ensure there were no discrepancies in the data.

\section{Leading Health Indicators (LHIs).}

Each article was reviewed for discussion of LHIs. Some articles were focused on an LHI issue while others merely presented LHIs as they related to a different health-related topic. For example, an article discussing oral health explained the relationship of tobacco use not as a modifiable risk factor but as a contributing factor to overall oral health.

\section{Sources of information.}

The credibility of sources was evaluated through information presented in each article. Researchers searched for expert quotes from MDs or $\mathrm{PhDs}$, research institutions where studies were conducted, government sources, relevant foundations, or references to professional refereed journals.

\section{Incidence/prevalence statistic.}

Each article was reviewed for the presentation of statistics relevant to the LHIs. Examples of such epidemiological data included rates based on sex, race/ethnicity, and magnitude of morbidity and mortality.

\section{Risk factor analysis.}

Risk factor data was collected for modifiable, non-modifiable, and controversial risk factors. Modifiable risk factors included practices such as sedentary lifestyle, dietary behaviors, cigarette smoking, and excessive alcohol consumption. Non-modifiable risk factors included items such as genetics, sex, race and ethnicity, and age. Controversial risk factors included items or practices that are not generally accepted among health professionals as being influential in the development of a health concern.

\section{Prevention measures.}

Prevention behaviors presented in each article were collected by researchers and categorized into primary, secondary, and tertiary prevention measures. Examples of prevention behaviors included regular physical activity (primary prevention), screenings (secondary prevention) and medications or surgery (tertiary prevention).

Data were entered into the Statistical Package for Social Sciences (SPSS) for Windows version 16.0 (SPSS Inc., 2008). Cross-tabulations, frequencies, and percentages were computed for each category.

\section{Results}

Fifty-five articles related to LHI topics were obtained from four magazines reviewed with publication dates between 2005 and 2008 . Thirteen (23.6\%) articles were published in Reader's Digest, 13 (23.6\%) in Time, 11 (20\%) in Newsweek, and 18 (32.7\%) in U.S. News and World Report. Factual information was presented in $49(89.1 \%)$ of the articles, two articles were anecdotal (3.6\%), and the remaining four articles consisted of a combination of factual and anecdotal information. Distribution of publication dates included 5 articles in 2005, 12 articles in 2006, 16 articles in 2007, and 22 articles in 2008.

Each of the ten LHIs was addressed in at least one article with the exception of substance abuse. The most frequent LHIs addressed were overweight and obesity in $21.8 \%$ of the articles $(n=12)$ and mental health in $18.2 \%$ of the articles $(n=10)$ [See Table 3]. The most commonly reported mental health issue presented was stress in nine of the mental health related articles. Many articles identified more than one source of information with experts (i.e., MDs or PhDs) as the most frequent source of information in $92.7 \%$ of the articles. Other sources of information included research institutions (40.0\%), government sources $(27.3 \%)$, refereed journals $(23.6 \%)$, and foundations $(12.7 \%)$.

Incidence and prevalence statistics were discussed in a number of the articles (58.2\%) with the general magnitude of morbidity and mortality being cited most often. Demographic characteristics discussed included sex (3.6\%), age $(3.6 \%)$, and race or ethnicity (9\%). Risk factors were also discussed in several of the articles reviewed. Modifiable risk factors were 
Table 3

Leading Health Indicators (LHIs), Sources of Information, and Prevention Measures Presented in Select General Readership Magazines

\begin{tabular}{lrr}
\hline Content Analysis & n & \% \\
\hline Leading Health Indicators (LHIs) (n=55) & 9 & 16.4 \\
Physical Activity & 12 & 21.8 \\
Overweight and Obesity & 3 & 5.5 \\
Tobacco Use & 0 & 0.0 \\
Substance Abuse & 2 & 3.6 \\
Responsible Sexual Behavior & 10 & 18.2 \\
Mental Health & 7 & 12.7 \\
Injury and Violence & 5 & 9.1 \\
Environmental Quality & 3 & 5.5 \\
Immunization & 4 & 7.3 \\
Access to Health Care & & \\
Sources of Information & & 92.7 \\
Experts & 51 & 40.0 \\
Research Institutions & 22 & 27.3 \\
Government Sources & 15 & 12.7 \\
Foundations & 7 & 23.6 \\
Refereed Journals & 13 & \\
Prevention Measures (n=46) & & 10.9 \\
\hline Primary Prevention & & \\
Secondary Prevention & 41 & \\
Tertiary Prevention & 5 & \\
\hline
\end{tabular}

presented in $21.8 \%$ of the articles $(n=12)$ and non-modifiable risk factors were presented in $14.5 \%$ of the articles $(n=8)$. The most commonly mentioned modifiable risk factors included cigarette smoking, sedentary lifestyle, and dietary behaviors.

Prevention measures were discussed in $83.6 \%$ $(n=46)$ articles [See Table 3]. Primary prevention measures were most frequently reported in $89.1 \%(n=41)$ articles followed by tertiary prevention measures in $17.4 \% \quad(n=8)$ articles The most frequently mentioned primary prevention measures included dietary modifications and physical activity. However, specific guidelines for either of these prevention measures were presented in only 10 articles. The most frequently mentioned tertiary prevention measure presented was surgery.

\section{Discussion}

Magazines play an important role in health information dissemination. However, the results of this study found these four magazines published an average of only 3.4 articles per 
year that contained any information regarding at least one of the ten LHIs. Considering the importance of LHIs, and the fact that all four magazines release at least one issue per month, with three of these titles publishing an issue every week, the coverage of major health concerns identified by the U.S. government could be increased.

Sources of information utilized by the authors of the reviewed articles tended to be credible, with many articles citing the information presented. Unfortunately, more than a few instances arose in which the reporting of research findings were inaccurately printed (e.g., review of the cited study did not mirror the data presented in the article) or the expert consulted for the article was an inappropriate source of information. For example, one article had the expert for tobacco cessation as a certified podiatrist. Coordination between health educators and members of the press regarding the interpretation of scientific research can enhance the quality of general readership articles. Additionally, utilization of the most valid and reliable sources of information is necessary to prevent possible confusion among magazine readers, who are likely inundated with numerous other sources of information such as the Internet, friends and family, newspapers, and anecdotal stories.

Statistics regarding incidence and prevalence were not presented in a thorough manner in many of the articles reviewed. While the general magnitude of morbidity and mortality were cited most often, a lack of demographic specificity could have negatively influenced the reader's perceived severity of one of the major health concerns in the United States, or the personal relevance of the issue. This also holds true with the low level of text devoted to modifiable and non-modifiable risk factors. Less than one quarter of the articles identified a risk factor that the reader could address that would reduce their personal risk for a disease or chronic condition. This lack of information in an article could present the reader with an impression of low urgency in addressing the health issue, or could leave the reader believing there is nothing that can be done on their part to address the concern. Failure to present information regarding modifiable and non-modifiable risk factors goes against the premise of LHIs, as they are selected partially for their ability to motivate behavioral action (US DHHS, 2000). Such action cannot be motivated if one is unaware of what action is to be taken.

Prevention measures, however, were presented in the majority of articles reviewed. These findings are encouraging given that primary prevention measures were the most frequently cited and primary prevention is the best defense against many chronic diseases and conditions. Yet, with the presentation of these prevention measures, it was left to the reader to discern that the lack of participating in various prevention measures (e.g., physical activity) was therefore a modifiable risk factor. Furthermore, the importance of secondary prevention measures (i.e., screenings) did not receive much attention in the articles reviewed. This was surprising in that the two most discussed LHIs were mental health and overweight and obesity. Concerns regarding these two LHIs arise early and various screening methods are available to assist a health care provider and individual with identifying possible problems. With the adoption of the 2010 Affordable Care Act, there is great opportunity for health educators to work with various media outlets, such as magazines, to help readers become more aware of the importance of all levels of prevention and the various resources available to acquire different levels of prevention services.

It appears that reporting of LHIs, a set of ten high-priority public health issues in the United States, in magazines is not consistent. Future coverage of these universal and high-priority areas should provide greater detail when reporting risks and prevention measures. Incidence and prevalence rates of health issues should be presented at a minimum by sex, age, and race/ethnicity. Such detailed coverage will enhance the personal importance of a health issue and may encourage discussions between qualified healthcare professionals and patients.

\section{Limitations}

Limitations of this study include the small number of magazines reviewed for health- 
related articles. The selection criteria used to identify magazine titles for review resulted in a limited number of publications. However, the total circulation rate for all four magazines reviewed exceeded 18 million readers. Another limitation is that the type of magazines reviewed was not well-balanced, as three out of the four titles were national news weekly publications in which a variety of current topics may be covered, thereby limiting the available print space for health-related content. While the magazine titles reviewed for this study draw a broad readership, the demographics for these publications showed the readership to be older and more affluent than the typical U.S. magazine reader. As such, the generalizability of our findings, due to the similarity of the publications and the populations who choose to read these publications, are limited.

\section{Practice Implications}

Magazines are a media source that consumers of various educational levels, income levels, and racial or ethnic backgrounds utilize for information. Magazine Publishers of America (n.d.) reported an increase in the readership of magazines by seven percent from 1997-2006, even with increased access to the Internet, instant messaging, podcasts and satellite radio. While print magazines are still widely circulated (including subscriptions and newsstand dissemination), most publishers have added access to the Internet-version of the magazine for free to subscribers. This expansion of magazine content to the Internet further increases the potential reach and implications of materials presented to consumers about various health topics.

Health educators should make a concerted effort to work with the popular press to improve the quality and accuracy of health information presented in magazines. While not everyone reads magazines, a large portion of the U.S. society does as evidenced by the highest magazine subscription rate in ten years being reported in 2008 (Association of Magazine Media, n.d.). Additionally, according to data from the Experion Simmons Multi-Media Engagement Study (2010), magazines continue to score significantly higher than TV or the internet in ad receptivity as well as all other engagement dimensions, including trustworthiness and inspirational capacity. A health educator working with article authors for various magazines can bring together the private and public sectors in their efforts to advance the awareness of the these ten high-priority public health issues in the United States. Such efforts may include interviews conducted about one's research, networking with publication personnel, writing columns for various publications (even at a local level), and sending letters to the editor of publications when information is incorrect. Each of these advocacy efforts falls within the professional responsibilities of a health educator.

\section{References}

Anderson, J. O., Mullins, R. M., Siahpush, M., Spittal, M. J., Wakefield, M. (2009). Mass media campaign improves cervical screening across all socio-economic groups. Health Education Research, 24, 867-75.

Association of Magazine Media. (n.d.). Magazine Media Factbook. Retrieved from: http://www.magazine.org/advertising/magazine-media-factbook/. Accessed August 14, 2011.

Botta, R. A. (2003). For your health? The relationship between magazine reading and adolescents' body image and eating disturbances. Sex Roles, 48(9/10), 389-399.

Breslow, L. (Ed.). (2002). Encyclopedia of Public Health. Gale Cengage. Retrieved from: http://www.enotes.com/public-health-encyclopedia/media-advocacy. Accessed August 14, 2011.

Dutta-Bergman, M. J. (2004a). Primary sources of health information: Comparisons in the domain of health attitudes, health cognitions, and health behaviors. Health Communication, 16(3), 273-288.

Dutta-Bergman, M. J. (2004b). A descriptive narrative of healthy eating: A social marketing approach using osychographics. Health Marketing Quarterly, 20, 81-101. 
Experion Information Solutions, Inc. (2010). Experion Simmons multi-media engagement study. Retrieved from: http://www.experian.com/simmons-research/multimedia-engagement-study.html. Accessed July 11, 2011.

Frost, K., Frank, E., \& Maibach, E. (1997). Relative risk in the news media: A quantification of misrepresentation. American Journal of Public Health, 87, 842-845.

Grilli, R., Ramsay, C., \& Minozzi, S. (2002). Mass media interventions: effects on health services utilization (Review). Cochrane Database of Systematic Reviews, Issue 1. Art. No.: CD000389. Retrieved from: http://www2.cochrane.org/reviews/en/ab000389.html. Accessed June 5, 2010.

Hay, J., Coups, E. J., Ford, J., \& DiBonaventura, M. (2009). Exposure to mass media health information, skin cancer beliefs, and sun protection behaviors in a United States probability sample. Journal of the American Academy of Dermatology, 61, 783-792.

Hornik, R., Jacobsohn, L., Orwin, R., Piesse, A., Kalton, G. (2008). Effects of the National Youth AntiDrug Media Campaign on youths. American Journal of Public Health, 98, 2229-36.

Magazine Publishers of America. (n.d.). 10-year magazine readership trend 1997-2006. (White Paper). Retrieved from: http://www.magazine.org/.../TenYrReaderTrend97-06\%2011-27-06.doc. Accessed June 15, 2010.

Maibach, E. (2007). The influence of the median environment on physical activity: Looking for the big picture. American Journal of Health Promotion, 21, 353-362.

Martinez-Gonzalez, M. A., Gual, P., Lahortiga, F., Alonso, Y., Irala-Estevez, J., \& Cervera, S. (2003). Parental factors, mass media influences, and the onset of eating disorders in a prospective population-based cohort. Pediatrics, 111, 315-320.

McCombs, M. E., \& Shaw, D. L. (1972). The agenda-setting function of mass media. Public Opinion Quarterly, 36, 176-187.

Media Management Center of Northwestern University. (2004). Highlights from the magazine reader experience study tool kit: The 39 magazine experiences and magazine usage drivers by demographics. Retrieved from: http://www.magazine.org/content/files/section2.pdf. Accessed August 14, 2011.

Noar, S. M., Palmgreen, P., Chabot, M., Dobransky, N., Zimmerman, R. S. (2009). A 10-year systematic review of HIV/AIDS mass communication campaigns: Have we made progress? Journal of Health Communication, 14, 15-42.

Phillips, D.P. (1974). The influence of suggestion on suicide. American Sociological Review, 39, 340-54.

Rogers, A., Hassell, K., \& Nicolaas, G. (1999). Demanding patients: Analysing the use of primary care. Buckingham, UK: Open University Press.

Schiavo, R. (2007). Health communication: From theory to practice. San Francisco, CA: Jossey-Bass.

Summerlin-Long, S. K., Goldstein, A. O., Davis J., \& Shah, V. (2009). Promoting tobacco-free school policies through a statewide media campaign. Journal of School Health,79, 184-192.

Wallace, L. S., \& Ballard, J. E. (2003). Osteoporosis coverage in selected women's magazine and newspapers, 1998-2001. American Journal of Health Behavior, 27(1), 75-83.

Wallack, L., \& Dorfman, L. (1996). Media Advocacy: A strategy for advancing policy and promoting health. Health Education and Behavior, 23, 293-317

World Health Organization (WHO). (1986). Ottawa Charter for Health Promotion. Retrieved from: http://www.who.int/hpr/NPH/docs/ottawa_charter_hp.pdf. Accessed June 5, 2010.

Wright, K., Sparks, L., \& O'Hair, D. (2008). Health communication in the $21^{\text {st }}$ century. San Francisco, CA: Wiley-Blackwell.

U.S. Department of Health and Human Services. (2000). What are the Leading Health Indicators? Retrieved from: http://www.healthypeople.gov/LHI/lhiwhat.htm. Accessed September 19, 2008. 


\author{
Author Information \\ Jeanne Freeman, PhD, CHES* \\ Western Washington University \\ PEHR Department \\ 516 High Street \\ Carver Gym \#102 \\ Bellingham, WA 98225-9067 \\ Phone: (360) 650-2125 \\ Fax: (360) 650-7447 \\ Email: Jeanne.Freeman@wwu.edu \\ Ying Li, PhD, CHES \\ Western Washington University \\ PEHR Department \\ * corresponding author
}

